\title{
Consequences of Pre-Marital Sex among the Youth a Study of University of Maiduguri
}

\author{
Dr Musa Abdullahi PhD \& Abdullah Umar
}

\begin{abstract}
This study was conducted in the University of Maiduguri. One of the Goals of the MDGs is to reduce HIV/STIs among the general population in the society. In this context it is important to understand why youth still engage in risky sexual behavior and the effects it has on them. The study focused on the effects and consequence of engaging in pre-marital sex among the youth of University of Maiduguri. The data were collected using multi methods - Survey, Focus Group Discussion and review of University security records. The stratified random technique was used to draw respondents from a sampling frame sourced from the University Information Management Unit. The sample size is 318 (286 for the survey and 32 focus group participants) The SSPS software was used in the analysis of the data. Findings revealed that pre-marital sex among the youth in the University has a number of effects and consequences on the youth. Some of the consequences include HIV/STIs, Regrets, Unwanted pregnancy, loss of self respect, loss of family support, Depression and victims to rituals among others. The study recommends Sex Education courses in all institutions of learning. Government should also partner with NGOs and embark on advocacy and campaign on the need to sustain sex free life and dicourage advocates of use of condom with sex. The University authority should live up to its responsibility as a custodian of youth in its care. Effective supervision of both academic and social life of youth in the University by the authorities and regular conferences and workshops by the authority, Students Union, ASUU, NASU and other associations on the Dangers of Pre-marital Sex, are some of the recommendations put forward.
\end{abstract}

\section{Introduction}

One of the Goals of the MDGs is combating HIV/AIDs, malaria and other diseases among the general population in the society by 2015 . In this context it is important to understand why youth still engage in risky sexual behavior and examine the effects it has on them. The university, as a centre for character and learning, the society expects the university to inculcate the moral values of the larger society especially in promoting desirable sexual behavior. This is to be achieved through teaching and learning, on the one hand and through rules and regulations, on the other. Students learn new behavior in order to adjust to the demands of the new environment. Each student comes to the university with his/her own perspective of life, relative to his social background. Because of the multi ethnic and social nature of the University environment, there is thus the likelihood of finding carriers of deviant norms who possibly teach others in the process of daily association.

Students, according to the Dean Students Affairs of University of Maiduguri, Ibrahirn (2003), suffer from physical and emotional pains of sexual assaults, most of which were not reported to school authorities for reasons only known to them. The attitude of not reporting the acts further exposes other students to greater danger and health risks. It equally encourages the emergence of pre-marital sex in institutions of learning.

Pre-marital sex is an act of deviation. A deviant act is used here to refer to departure from societal norms that attract social disapproval which is likely to elicit negative sanctions. When students of different ages, nationalities, ethnic and religious backgrounds and status are brought together in a higher institutions environment, opportunities exist for sexual relationship. Pre-marital sex is a violation of sexual norms and values of a society. Abdullahi (2004) explained that values are conceptions of what is right (good, desirable and proper) and wrong (bad, undesirable and improper). The Hausa culture, he further observed, values the institution of the family with proscriptive norms that prohibit pre-marital sex like pre-marital sex.

The concepts of a University student and University education have changed over the years. Students, Ibrahim (2003) observed, seem to value free sexual life on campus. Unlike students of the 1970s and 1980s, most students in present day Nigeria are likely to be of the view that life has little or no meaning without sexual interaction on campus. Fromm (1991) views the modern world as being strangulated between "robotism and humanism" life, he observed has no meaning; there is no joy, no reality, and no faith. In a situation like this, individuals resort to the comforts of the body, particularly in a university environment. Moreover, universities in modern Nigeria seem to have lost their focus in (lie area of student's discipline.

The value system of most Nigerian societies has created a barrier between parents and their children in matters relating to sex. In most societies, it is a taboo to talk about sex. Our communities and religious leaders preach daily against what is called 'bad behaviors' like alcoholism, corruption, hoarding, and etc but seldom talk 
about sex education. It is very easy to talk to the student to abstain from sex until marriage, but within the university environment it will be difficult to enforce such values because of the multiethnic and social nature of the environment. Societies have developed and shaped their value systems upon which social life is regulated. Societal norms, that is, codes of behavior which the members of the society are expected to adhere enforce most of the values. The regulation of social values is the responsibility of the family first, then the extended social networks like educational institutions. Values are fundamental to our attitudes and dispositions towards issues and things.

The objective of this paper therefore is to explain the consequences of pre-marital sex among the youth of the University of Maiduguri. The data were collected using multi methods - Survey, Focus Group Discussion and review of University security records. The stratified random technique was used to draw respondents from a sampling frame sourced from the University Information Management Unit. The sample size is 318 (286 for the survey and 32 focus group participants)

\section{Some Explanations}

Maiduguri is a predominantly Muslim community with strict adherences to religious moral values. Issues relating to sex activities are seriously monitored and great emphasis is attached to the need to abstain from sexual activities outside marriage. Permissible sexual relation is restricted to marriage life cohabitation. The Maiduguri community, like in most northern societies, encourages its unmarried population not to engage in any form of sexual activity before marriage. Great value is attached to virginity of both males and females. Any girl for instance, that was found to he virgin by her husband is highly respected in the community which sees her as a symbol of purity. From birth to adulthood, parents teach and monitor their children to abstain from any form of sexual activity. The society in some cases sanctions violators of sexual norms. Sexual acts like premarital sex, adultery, rape, homosexuality, smooching and the like are considered abomination and against social norms. Other related activities like watching naked bodies, exposing of sexually attractive organs like the female breast are seriously condemned. The community does not allow any form of body exposure that will attract the eyes or the attention of the public. It was for this reason that greater value is attached to decent dressing and control of sexual urge. Men and women are expected to put on dress that will not show any part of their sexual organs. Men to put on long dress with trousers, while women to put on dress that will cover all the body, except the face, feet and hands. Any dress contrary to this is considered abnormal and it amounts to a kind of exhibitionism (Aji. 2004).

Sexual control is practiced for the sake of the larger society and the individuals. Davidmarin, (1998) argued that yhe family is the basic unit of society and its strength depends on the ability of the partners to control sexual urge which distinguishes humans from animals. Human sexual behavior, like many other kinds of activity engaged in by human beings is generally governed by social rules that are culturally specific and vary widely (Wikipedia, 2007).

The existence of pre-marital sex among the youth in the university environment can be attributed to a variety of factors. These factors include economic factors, social issues, peer pressure, the mass media influence, and search for academic advantage.

The existence of pre-marital sex among students seems to be rampant in Nigerian institutions of higher learning. Warner (1973) observed that sex before marriage is seen as normal and a pleasurable satisfaction which young adults experience. The university environment allows freer sexual activities and this is against moral values of the community. The University is witnessing he prevalence of pre-marital sex, homosexuals, rape and adultery in the campus. Public out-cry against these vices is increasing and significant members of tile community felt that something has to be done. Odoemelan (1996) observed that inappropriate sexual behaviors and consequences of such behaviors constitute enormous problems.

\section{Some Related Literature}

Some of the literature on sexual behavior failed to establish the fact that some of our sexual activities like pre-marital sex, adultery and homosexuality constitute a serious social problem and a threat to civilization. lkpe (2003), Twa-Twa (1997) and Johnson (2007), studied and reported the existence of sexual activities among undergraduates and they all advise on the need to use condom. Lack of condemnation of such vices as deviant acts by some scholars encourages pre-marital sex. Most writers on sexual behavior end up as interventionist strategists to the sponsors of their study by encouraging the use of condom and other methods for safe sex.

Sex relations appear as one of the most important aspects of students' life in the university. Members of the larger society are no exception either. Sex, Afi (1977) argues, is crucial to social survival. True as the statement may be, it is equally important to note that sex is bound up in deep psychological gratifications. Societal norms and values have placed restrictions and conditions for engaging in sexual act. By such normative restrictions, significant members of the population will be deprived of sexual gratifications. It was for the interest of the individual and the society at large that sexual relationships sanctioned and regulated. Sex is 
capable of impelling individuals toward behavior which may disrupt the relationship upon which social life depends.

Robertson (I989) observes that societies of the West have shrouded sexual behavior in myth, taboo and ignorance. Research interest into the field of sex began in the late I940s to early 1950s. It was Kinsey (1948) who first carried out elaborate investigation on sexual behavior, tie faced condemnation from many religious organizations and media. In Africa, most of our traditional leaders and parents still find it difficult to publicly speak on sexual practices, despite its seeming implications to youths. This attitude has led our children to acquire sexual knowledge from the media and peers, particularly in a learning environment.

Robertson further argued that sex in itself may not he immoral, but the circumstance under which the act is carried out could be immoral. When the sex act is carried out outside the conventional sexual norms of the society or the community, it becomes a deviant act and inappropriate when measured against the general standards of behavior. Robertson's view is shared by Kuria (1987) and Clinard and Meier, (1998). Clinard and Meier argue that sex is a natural part of life and is important to the society, because it perpetuates species.

Potts arid Selman (1979) argued that adolescent sexuality was not a problem in Africa. But now, it is. The society defines maturity rites of passage. But it is not the case in contemporary times. Adolescents are carrying pregnancies and terminating pregnancies when they are yet to marry. Sex and reproductive behavior, they argue, are molded by cultural and social forces but moral commandments regarding sex tend to be cut deep on the 'tablets' of social behavior.

\section{Consequences Of Pre-Marital Sex}

In this section an attempt is made analyze identified consequences of pre-marital sex. These consequences include, the feeling of regret, drug use, unwanted pregnancy, bondage, loss of self aspect, corruption of character, depression, fear of future commitment, STDs, feeling of guilt, poor academic performance, loss of family/parents support and victim of rituals,. A level four male discussant said;

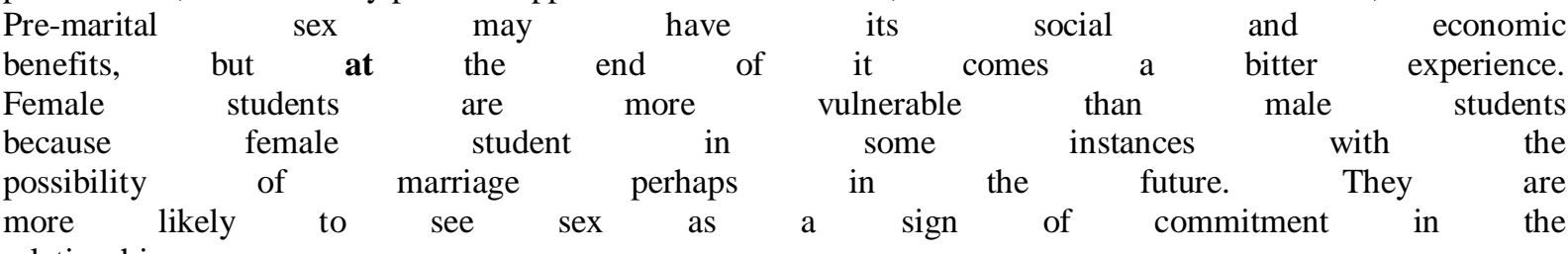
relationship.

Table 1: Respondents Distribution on the Consequences of Pre-marital sex

\begin{tabular}{lccc}
\hline Category of Response & Stated & Not Stated & Total \\
\hline Regret & $123(43 \%)$ & $163(57 \%)$ & $286(100 \%)$ \\
Drug Abuse & $92(32 \%)$ & $194(68 \%)$ & $286(100 \%)$ \\
Unwanted Pregnancy & $194(68 \%)$ & $92(32 \%)$ & $286(100 \%)$ \\
$\quad$ Bondage & $66(23 \%)$ & $220(77 \%)$ & $286(100 \%)$ \\
Loss of self Respect & $163(57 \%)$ & $123(43 \%)$ & $286(100 \%)$ \\
$\quad$ Corruption of Character & $203(71 \%)$ & $83(29 \%)$ & $286(100 \%)$ \\
Depression & $194(68 \%)$ & $92(32 \%)$ & $286(100 \%)$ \\
Fear of Future Commitment & $106(37 \%)$ & $180(63 \%)$ & $286(100 \%)$ \\
$\quad$ Sexually Transmitted Infections & $266(93 \%)$ & $20(7 \%)$ & $286(100 \%)$ \\
Guilt $\quad 109(38 \%)$ & $177(62 \%)$ & $286(100 \%)$ \\
Poor Academic Performance & $80(28 \%)$ & $206(72 \%)$ & $286(100 \%)$ \\
Loss of Family and Parental Support & $72(25 \%)$ & $214(75 \%)$ & $286(100 \%)$ \\
Victims of Ritualists & $149(52 \%)$ & $137(48 \%)$ & $286(100 \%)$
\end{tabular}

Figures in bracket are percentage

\section{Regret}

The findings of the study reveals that $43 \%$ of the respondents posited that sex deviant acts can lead to regrets. Discussants argued that most of the upper level students regret their premarital sexual acts practiced when they were at lower academic levels. A level two female discussant explained that she regretted dating a final year student who took the best part of her life and dumped her for another girl. Another female discussant said.

I am young but I feel old whenever I remember the day I lost my virginity to a member only social club whom I met that very day.

Another female discussant narrated the story of her room mate and a close friend thus: 
She never had a boyfriend before coming to the university. She was excited when one of the 'happening guys' on campus asked her out for a picnic at Lake Alau. After two weeks, the boy asked her to have sex. 1 discouraged her and she was reluctant. He was persistent and she slept with him. That was the last. time she saw him. She is now regretting even coining to the university.

\section{Drug Abuse}

Drug use among male students is very common according to the respondents. It is also harmful and needs the authority's attention explained by respondents. The study reveals that $32 \%$ of respondents stated that pre-marital sex can lead to drug use. Discussants argued that various drugs were used by students for enhancing sex performance which has made some of the students become drug addicts. In some cases students take drugs after their relationship has broken. A male discussant explains:

Most students these days go on alcohol, hard drugs and smoking.. .they do not really want to, but to ease sorrow of sex acts and disappointments, they have to take it. They manage their regrets.

A male discussant explained that his room mate once got drunk deliberately in order to have sex with the girlfriend of their room mate who always brought different girls and allow them to watch him through the window. Since that day according to him, the student developed a drinking habit and he has become addicted to it.

\section{Unwanted Pregnancy}

The findings of the study show that $68 \%$ of respondents posited that engaging in premarital sex can lead to unwanted pregnancy. Discussants argued that there were cases where students dropped out of University of Maiduguri because of being pregnant or were caught in the attempt to abort pregnancy or abandon babies on campus. The practice of sharp-sharp sex was said to contribute for some unwanted pregnancies among students. Sharp-Sharp is carried out mostly in party venues and some of them are drunk and engage in sex without condom, and with non dating persons, as argued by most of the discussants across groups.

\section{Bondage}

This is a situation where a student (male or female) is expected to always have sex on regular bases with an individual because the person is in possession of ones secret or knows one's weaknesses. Table I shows that $23 \%$ of the respondents posited pre-marital sex can lead to bondage. A female discussant who brought a letter during the FGD session, requested if she can read a letter her friend wrote her. She summarized the content of the letter as follows:

...since the first night, he expects us to have sex on every date, as if we are married. When I do not feel like doing it, he will insist on oral and we end tip in an argument. It's like I owe it to him. I do not think he loves me. I know deep down that I am not in love with him either and this makes me feel cheap. It is like a bond between us I can't help myself...

\section{Loss of Self Respect}

The study shows that $57 \%$ of the respondents posited that engaging in pre-marital sex leads to loss of sell respect. A level two female discussant explained that when a person falls so low and allow him/her to he used as a sex object he/she will certainly lose self respect and personality in the eyes of both person and the larger society. Loss of self respect also comes when students happen to contacts STDS or was raped in the case of female students. Female students who engage in group sex, sharp-sharp sex or being watched by others while having sex, usually suffer a loss of self-esteem. Students who had abortion or got pregnant equally suffer from loss of self-esteem. A male discussant explained that he was very much in love with a girl and he was ready to do anything to have her as future partner, but lie changed his mind when he had sex with her. He said: ‘

I finally got her and had sex with her, actually it was in my car; my - feelings for her diminished, I thought she was one of the hottest and difficult to get I figured out that there had probably been a dozen guys before me. That realization took away all the respect I had for her I couldn't respect someone who gave in easily as she did in my car.

\section{Corruption of Character}

This study shows that engaging in pre-marital sex can lead to corruption of a person's character. The study reveals that $71 \%$ of the respondents opined so, and as some of them further explained that it diminishes good virtues such as respect, honesty, care, fairness and self control. A level three male discussant says:

When individuals treat others as sex objects and exploit them for their own pleasure, they not only lose self respect, they corrupt their character and debase their sexuality in the process. Students lie about themselves and their family backgrounds if they think it will help them have sex. Sex frequently corrupts character by leading people to tell lies.

Apart from that, discussants observed that the GSM handset further facilitates lies and were equally used to send sexual images to each other, or send a text message to some one requesting him or her for sex. It is 
common to hear student saying "I want to fuck", "fuck your ass'. "bitch" etc; these are elements of corrupted character on campus. A female discussant confesses:

I was sent a male organ text by a friend with a message 'do you mind' lie cannot tell me this directly and he cannot zip down his trouser to show his organ, but with GSM, it is easily done and it corrupts a person.

In most pre-marital sex situations, sex is not tied to love and commitment. This undermines character by subverting self-control, respect and responsibility. Thus, sex that is supposed to be practiced normatively has lost its meaning. and is trivialized and degraded.

\section{Depression}

Survey data revealed that most victims of rape, those who had unwanted pregnancies and those caught in acts of sodomy tend to be more depressed than others who engage in premarital sex. Table 4.7 shows that $68 \%$ of the respondents believed that engaging in premarital sex can lead to depression. Some of respondents indicated that depression as a result of pre-marital sex is particularly associated with students who engage iii sex for economic reasons, love reasons and influence reasons. A female discussant said that engaging in sex for the sake of money is very depressing because in some cases one is treated like animal because they pay for it. A male discussant explained further:

It diminishes one (a person) because before one starts growing old, it starts showing on his his/her face. They might get involved in an activity where they get infected with viruses. Sometimes they do sleep with snakes and other animals for rituals. This and so many other things make them not to be able to give birth again. They will end up having no children and that is very depressing.

The emotional stress of broken sexual relationships also causes depression. Young students tend to invest more in a relationship that seem real at first, and then suffer deeper pain and hurt when the relationship comes to an end. In some cases drug use and alcohol consumption were said to he coping strategies or remedies for the depression the individual was passing through.

\section{Fear of Future Commitment}

The table shows that $37 \%$ of the respondents posited that engaging in pre-marital sex may lead to fear of future commitment to other relationships. Smooth sex relations can turn bad. Sex can have another kind of emotional consequence. Pre-marital sex relationships can bring bitter experience in the attempt to form normal sex relationships. Emotions like anger, impatience. Jealousy and selfishness surfaces particularly when one partner feels he/she has had enough of it. A male discussant explained how his friend was dumped by a sugar mummy and ever since, he kept his distance from women and even vowed not to get married. According to a male discussant:

She dumped him by the time she satisfied all her needs. He is addicted to good material things and now finds life unbearable and he took an oath never to have any relationship with any woman again.

\section{HIV/STIS}

The study shows that $93 \%$ of respondents posited that engaging in pre-marital sex can lead to HIV/STls. Majority of the discussants in the FGD groups argued along the same hue and identified some of the STIs which include herpes, (sores and painful swelling of genital), gonorrhea, (pelvic pain and painful urination) and HIV (a virus that kills immune system) which are in existence among students. They further explained that those who engage in group sex, sharp-sharp sex and sodomy account for a greater proportion of STI's victims. ('Chlamydia and gonorrhea, a level four female discussant argued are common with female students. These diseases are life-threatening, painful and can cause infertility.

\section{Guilt}

The Table also shows that $38 \%$ of the respondents posited that engaging in pre-marital sex can lead to guilt. In as much as a sexual act can be pleasurable, it can also be the source of deep wounds and with feeling of guilt. A level four female discussant expatiates:

Guilt about past sexual act ends up crippling people when they become parents and most often they become very strict on their children's' sex behavior, which in turn makes such children curious about sex acts and thus easily get involved when the opportunity comes up.

Guilt is a form of regret, a feeling that a person has gone against his/her conscience or has done something morally wrong. Guilt comes as a result of the fear that parents are aware of ones sexual acts or would be upset if they knew one is having sex. Guilt may also stem from one's religious convictions. Such students, who were frustrated and stopped engaging in pre-marital sex, become "born again" sisters and brothers. A male discussant explained that his friend become a devoted Christian and always preaches against pre-marital sex when his girl friend told him that she was pregnant for him. A female discussant said: 
This first day I did it, I went home in shame and I could not be able to see my mother's eye for the first time because of the guilt in me. She knew at last as a woman, but afraid of my dad and the outcome of my action. I am still nursing the guilt in me. It's terrible when the guilt comes.

\section{Poor Academic Performance}

The table shows that $28 \%$ of the respondents posited that engaging in pre-marital sex can lead to poor academic performance. Majority of the discussants argued that engaging in pre-marital sex can affect academic performance. They further argued that most of those who regularly engage in pre-marital sex arc withdrawn from other departments earlier, while others were repealing. They run social clubs and are always after pleasures and they are not much bright, but they pollute others who may not be dull. A male discussant explained his friend's experience, which most of the discussants in the group agreed was a very common experience.

According to him:

When he had no girl friend he was very good academically. But when lie found a girl he dedicated most of his time for her. At the end of the session, his CGPA was low last session. We were preparing for exam when somebody called him to come and see something. On getting there he saw his girlfriend, playing with another man. lie came back and told me and lie was disturbed. He failed most of his course that session. IIe is carrying over the courses and regretting ever meeting that girl.

\section{Loss of Family Support}

Table I shows that $25 \%$ of the respondents opined that engaging in pre-marital sex may lead to loss of Parents support. Some respondents explain that SOC parents may reduce support be their sexually wayward children. Discussants equally argued that when parents are aware that their son/daughter engage in pie-marital sex or become aware of their being pregnant or hive contacted STIs, parents withdraw their support. Once parental support is withdrawn, the student becomes depressed, stressed and isolated from the campus community.

There was an incidence in 1999 when a female student was rejected by her parents for having unwanted pregnancy. She was also rejected by the boyfriend on the pretext that he is not sure whether he was responsible for the pregnancy. The students' union adviser had to take her to his house for three months before her relatives agreed to accommodate her and the baby. Majority of the discussants in the FGD groups observed that many female students and a few male students have lost family support as a result of their pre-marital sex acts. A level two male discussant said:

1 used to stay in a BQ belonging o one staff in [3iochemistry Department. I le has a son who drugged a remedial female student and slept with her the first night: The girl became pregnant and asked the boy to do something. lie brought his friend (a medical student) to perform D\&C, but the girl lost a lot of blood. The matter became serious and his father was informed by his junior sister. His father took the girl to the hospital and he sent out all of us in the BQ including his son with a warning to the son never to return to his house again.

\section{Victims to Ritualists}

As shown in Table I, $52 \%$ of the respondents believed that engaging in sex deviant act may lad one to be victim of ritalists. Majority of the discussants in the entire FGD group opined that those who engage in piemarital sex become easy targets for ritual activities. Most people who were looking for human parts for ritual purposes give huge amounts of money to greedy and materialistic students, who possibly would end up with missing part or parts of his/her body or even his life. There were reported cases (as revealed by security documents) involving students and this has been a matter of serious concern to the security division of the university. A female discussant explained that any relationship based on money has no benefit because the money cannot he there all the time. She said:

She is looking for money, the man is also looking for money and if she is unfortunate the man may use her for rituals. A case of monkey going to the market and never returns.

\section{Conclusion}

In summary, the data from the security documents, focus groups and the sampled respondents concur on the view that pre-marital sex may have its social and economic benefits, but at the end, it also comes with a bitter experience. Female students are more vulnerable than male students because female students in some instances think of sex as a way to show care, affection and love, with the possibility of marriage in future. They perceive sex as a sign of commitment in a relationship. The consequences as revealed by the study include unwanted pregnancy (68\%). STIs/HIV/AIDs (93\%), drug and alcohol consumption (32\%) and abortion, all of which are hereby seem to have biological effect in nature. The psychological consequences identified include depression (68\%). phobia (37\%), guilt (38\%), regrets $(43 \%)$, bondage $(23 \%)$ and stress. The social consequences are loss of family support, loss of self respect (57\%), corruption of character (71\%), poor academic performance $28 \%$ and alienation from peers, particularly room mates. 
These consequences are in harmony with the finding of NDHS (2005), FGN (2000) in Nigeria. Ejue and Effion (2005), Orji and Anikweze (1997) and lkpe (2003) in the University of Lagos which reveals that premarital sex leads to various forms of venereal diseases, unwanted pregnancies, death through abortion, sacrifice of educational opportunities among others. Malumfashi (2001), in his study on Adolescent Reproductive Health problems, made similar observations where he noted that premature sexual intercourse results in undesired pregnancies, unsafe abortions and STIs.

Thus, the consequences are thus biological (unwanted pregnancy, abortion, STIs and barrenness). Psychological (depression, phobia, guilt, regrets and stress), and social (loss of family support, poor academic performance, loss of self-respect, corruption of character, drug use, bondage and alienation from the larger society). Students who engage in pre-marital sex are likely to stiffer negatively from long term physical, emotional, social and moral consequences than students who choose not to engage in it. Pre-marital sex is thus riddled with multiple emotional and mental consequences.

\section{Recommendations}

I. The Nigerian University Commission (N.U.C) and the Federal Ministry of Education should develop a curriculum on sex education for institutions of high learning. This will enable students to understand the dangers associated with early sex and prepare them on how to manage sexual urges.

2. Government should tome out with a policy that will provide scholarship to students in the Universities on regular basis up to graduation. This will assist students and make them concentrate on their studies instead of going round and negotiating for sex for economic reasons.

3. Government should enforce dress codes in all higher institutions of learning through legislation. This will reduce sexual urge, rape and temptations that are in some instances facilitated by provocative and sexy dresses that some students put on.

In addition to the above, below are ways through which the University authority can overcome the prevalence of pre-marital sex in the university:

1. The university should stop accommodating students of the same socio-economic background in one room. Equally those who express interest of staying with specific individuals should not he honored.

2. The university authority should step up to its responsibility as a custodian of the students under their care, and monitor the activities of campus social clubs and review the policy regulating the conduct of campus social clubs.

3. The university should adhere strictly to its calendar of events and task departmental leaderships for its effective implementation.

4. The university should revise its policies on room visitations that allow female students to visit male students, from $6 \mathrm{am}$ to $10 \mathrm{pm}$ and conic up with rules governing sexual relationship on campus.

5 Security lights are to be provided at all areas that provide opportunities to students carry out their sex activities coupled with effective security patrol.

6 Students should be encourage by the authorities to organize seminars, debates, symposia and other related activities to help them build their academic potentials and resist deviant activities.

7. Parents should as a matter of responsibility, monitor and pay regular visits to their children in the universities and provide them with basic materials that will make their stay comfortable.

8. ASUU. NASU, SUG, departmental and state associations should monitor their constituencies and regularly organize workshops, seminars and conferences on sexual behavior in the University community and (he society in general.

\section{Reference}

[1] Abdullahi, S.A. (2004). Our Families, Their values, And Our Responsibilities, Some Insight into the Disintegration of' Family Values in Hausa Society. A Paper Presented at Pace Forum. Kano, Mambayya House, 2004

[2] Afi, H. A .( 1977). The Fanmily Sruciure. Maryland: Brentwood Press.

[3] Ajayi, A.J.F, (2002). 'Paths to the Sustainability of Higher Education in Nigeria'. Paths to Susiuinability of higher Education in Nigeria. Abula: SSAN.

[4] Aji, A. (2004). Moral Issues in Islam. The Role of Students and lecturers. Paper presented at 2004 MSS'Marhaha Week held at ElKanemi-Hall of University of Maiduguri.

[5] Clinard.M.B. and Meier, R.F. (1998). Sociology of Deviant Behavior 10" ed, Forth Worth: Harcourt Brace College Publishers

[6] Davidmann. .M. (1998). Family, Sex and the Individual. Retrieved June 10, 2004, from http://nsre.sfsu.edu/Index.c fm/?

[7] Fromm. F. (1991). The Same Society. London: Roueledge and Kegan Paul.

[8] Homans. G. C. (1 975). The Human Group. London: Routeledge and Kegan Paul.

[9] Ibrahim. G. (2003). Education and Responsibility, University Community: A Paper Presented at the 2003/2004 students orientation week at University of Maidtiguri, Maiduguri.

[10] Ikpe. F. B. (2003). "Sexual Negotiation in Tertiary institution in Nigeria" Lagos Journal of interdisciplinary. Journal of National Association of Academics vol. I Lagos.

[11] Johnson, B. (2007). Sexplosion on Campus. The News, Special Report, Lagos.

[12] Kinsey, A. C.. Pomeroy. W. B. \& Martin, C. E. (1948). Sexual Behavior in the Humnan mule. Philadelphia: W. B Saunders.

[13] Kuria. T. (1987). In McCarthy, B. \& McCarthy. E. (1993): Sexual Awareness New York: Carroll \& Graf 
[14] Odoemelan, A. (1996). Incidence and Management of Male and Female Sexuality, Maladjusted youngstars — Gender and counselling Implications. The counsellor, 14(2), 160-171.

[15] Potts. M. and Selman, P. (1979). Society and Fertility. Plymoulh: Macdonald and Evan Ltd.

[16] Robertson. I. (1989). Socieiv: A Brief Introduction. New York: Worth Publishers.

[17] Sheriff M. and Sheriff, C. W. (1964). Reference Groups: Exploration into Conformity and development of Adolescents. New York: Harper and Row Publishers.

[18] Twa-Twa, .J. M. (1997). "The Role of Environment in Sexual Activity of School Students in Tororo and Pallisa Districts of Uganda". Health Transition Review 7:67-81 (Suppl.)

[19] Warner, W. L. (1973). American Life: Dream and Reality. Chicago:University of Chicago Press.

[20] Wikipedia. (2007), History of Human Sexually. Retrieved February 13, 2007, from hup]/en.wikipçia.org/wiki/Hurnn-sexuaI behaviour. 